\title{
Trunk stabilization with sling training in osteoporosis patients — a randomized clinical trial
}

\author{
Guido Schröder • Andreas Knauerhase • \\ Guenther Kundt • Hans-Christof Schober
}

Received: 17 August 2011 / Accepted: 1 April 2013 /Published online: 5 May 2013

(C) European Group for Research into Elderly and Physical Activity (EGREPA) 2013

\begin{abstract}
Fractures due to osteoporosis are one of the principal causes of functional limitations, chronic pain, and greater morbidity in advanced age. In addition to bone risk factors for osteoporotic fractures include extraosseous causes such as falls or reduced neuromuscular capacity. Muscle and coordination exercises enhance the patients' abilities in daily life and prevent falls. In view of recent conclusions drawn from competitive sports, which stress the significance of the muscles of the trunk in respect of reducing back pain and optimizing posture, we used sling exercises to determine whether osteoporosis patients benefit from it and whether it is more advantageous than traditional physiotherapy. Fifty patients were randomized into two groups. Group A received traditional physiotherapy, while group B was given sling exercises, in each case twice a week for a period of 3 months. The results of treatment (prepost) were analyzed in terms of pain levels, mobility, trunk strength, and the shape of the back. After a further 3 months with no specific exercise treatment, we retested all patients in order to draw conclusions about the long-term effects of
\end{abstract}

Schröder and Schober carried out the concept and design, analysis and interpretation of data, acquisition of subjects, and preparation of the manuscript. Knauerhase participated in the acquisition of subjects and preparation of the manuscript. Kundt performed the statistical analysis.

G. Schröder $(\bowtie) \cdot$ H.-C. Schober $(\bowtie)$

Department of Internal Medicine, Klinikum Südstadt Rostock,

Südring 81, 18059 Rostock, Germany

e-mail: guido.schroeder1@gmx.net

e-mail: hans-christof.schober@kliniksued-rostock.de

A. Knauerhase

Department of Internal Medicine, University of Rostock,

E.-Heydemann-Str. 6, 18057 Rostock, Germany

\section{G. Kundt}

Institute for Biostatistics and Informatics in Medicine and Ageing Research, University of Rostock, E.-Heydemann-Str. 8, 18057

Rostock, Germany the two types of exercise. Forty-four patients ( $88 \%$ ) completed the study. Patients were assigned to small groups (a maximum of five patients in each group) and, thus, received individual attention and motivation. Positive training effects were achieved in both groups. Significantly better results as regards improvement of mobility and reduction of falls were registered in the sling exercise group.

Keywords Osteoporosis · Pain therapy · Fall risk reduction · Trunk strength $\cdot$ Sling exercise therapy

\section{Introduction}

Falls are a major health problem in patients with osteoporosis because they are associated with significant morbidity, pain, and a risk of fractures. The latter are frequently followed by immobilization and reduction of muscle and bone mass. Other consequences include isolation and restriction of independence, loss of autonomy, and diminished quality of life in advanced age [23]. A number of interventions have been developed to address this condition. The benefits of regular physical exercise include alleviation of pain, prevention of falls, and improvement of mobility and quality of life $[4,7,11,20,29,30]$. Fitness factors such as strength, stamina, and easy motion are encouraged. Given the geriatric aspect of osteoporosis, activation of the sensomotor system is important. Many elderly individuals suffer from comorbidities (such as deterioration of visual acuity or perception of contrast) which, however, culminate in physical imbalance only when combined with proprioception deficits. As recent advancements in sports medicine have proven the beneficial effects of sensomotor exercise on the regulation of posture and/or the frequency of falls [25, 31], we decided to use sling exercise therapy. The procedure was developed by Kirkesola [12] to treat motor problems and was established by Meier [14] for prevention as well as rehabilitation of professional German sportsmen. 


\section{Methods}

Design and randomization

Patients were recruited from outpatient osteoporosis clinics at Klinikum Südstadt Hospital and the University Hospital of Rostock. All study participants had proven osteoporosis (T-score $\leq-2.5$ ). Those who were unable to complete the entire training program during the period of the investigation were excluded from the analysis. Patients were randomized on a 1:1 basis. None of them had been on regular drugs for pain relief. The permuted block design was used for randomization [22]; block size was randomly selected. The randomization envelopes were numbered in ascending order. A proband to be randomized opened the envelope with the lowest number among all sealed envelopes.

\section{Intervention}

Over a period of 3 months, 44 patients with osteoporosis completed a twice-weekly 30 -min intensive exercise program designed to stabilize the trunk. Exercise sessions were performed under the supervision of a trained physiotherapist. Both groups completed a training program that consisted of five phases. Figure 1 shows the four main phases of sling training. The physiotherapy (PT) group performed similar exercises without slings (e.g., chair-rising exercises, pelvic lift, step-ups) (Fig. 1, sling training).

Phase 1 Systematic cardiovascular and neuromuscular warm-up (PT group: general keep-fit exercises; sling therapy (ST) group: step aerobics)

Phase 2 PT and ST groups: functional strength exercises focusing on correct posture

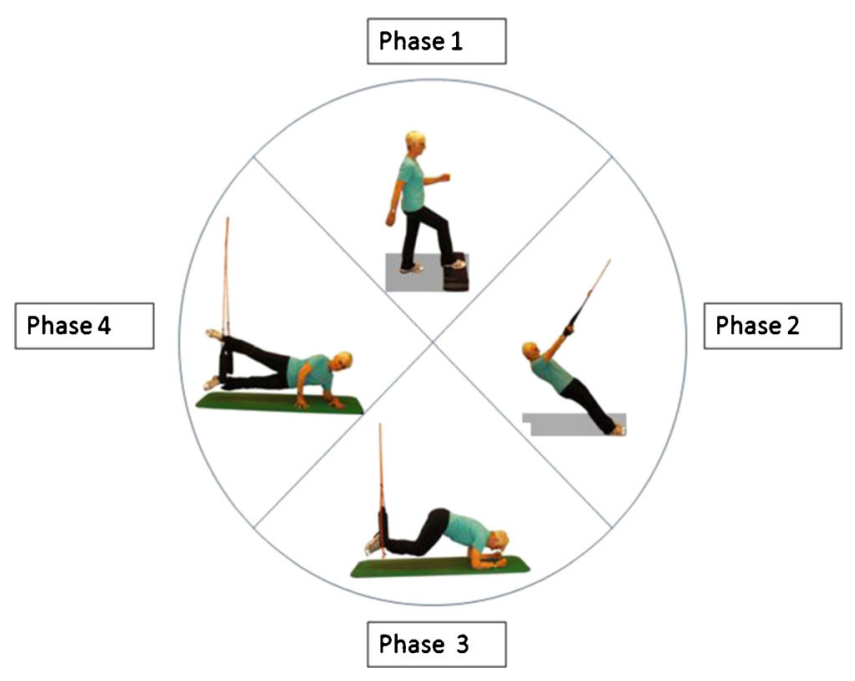

Fig. 1 The four main phases: group B
Phase 3 PT and ST groups: functional strength exercises for global surface muscles of the torso; ST group: dynamic sling exercise

Phase 4 Segmental stabilization (SST), both static and dynamic (PT group: exercise/medical ball; ST group: sling)

Phase 5 Stretching and relaxation

Each exercise session included all of the five phases.

\section{Clinical tests}

Clinical tests included the chair-rising test (CR test) and the timed up-and-go test (TUG test) $[3,19]$ as a means of assessing strength and coordination and identifying a higher risk of falls.

- CR test: The patient sits upright on a chair without arms, with his/her arms folded in front of the chest. The patient is asked to stand up and sit down five times in succession. The results of the test indicate whether the risk of falls is normal or high.

Time measured $\leq 10 \mathrm{~s} \rightarrow$ normal

Time measured $>10 \mathrm{~s} \rightarrow$ high risk of falling

- TUG test: The patient sits upright on a chair without arms. When instructed to do so by the test supervisor, the patient stands up, walks a distance of $3 \mathrm{~m}$, turns around, and sits down, thus returning to the starting position. The results of the test provide information about impairment of mobility.

Time measured $\leq 10 \mathrm{~s} \rightarrow$ normal

Time measured $>10 \mathrm{~s} \rightarrow$ high risk of falling

Pain

Subjective perception of pain during movement and pain at rest was scored using the numeric rating scale (NRS), which consists of 11 ratings from 0 (no pain) to 10 (worst imaginable pain). The patient selects a number from this scale to rate his/her pain. The NRS, a gold standard in geriatrics [2], was used before and after the training period as well as during follow-up.

\section{Video raster stereography}

Raster stereography is a computer-aided screening procedure used to generate a profile of the surface of the body without radiation [8]. A raster of parallel lines is projected onto the dorsal surface and is deformed by the surface contours of the body. Based on certain fixed points (Fig. 2: symmetry line of the spinous processes, vertebra 

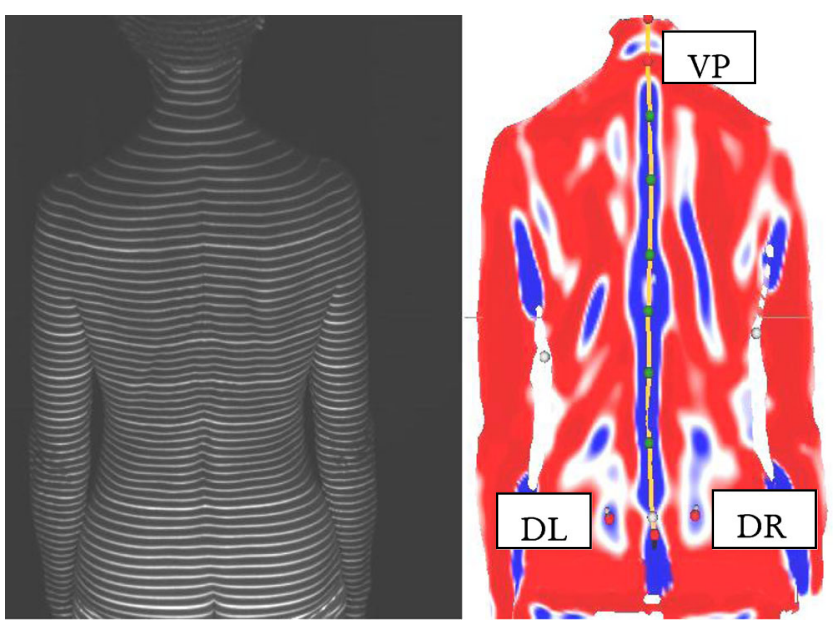

Fig. 2 Raster of parallel lines on the dorsal surface (left image); threedimensional view of the dorsal surface with convex (red) and concave (blue) surface areas (right image), vertebra prominens (VP), dimple left $(D L)$, and dimple right $(D R)$

prominens, left and right dimples, and sacrum point), the device generates a system of coordinates which corresponds to the shape of the body. Using triangulation, mathematical parameters are employed to calculate frontal and sagittal planes and surface rotation automatically. Video raster stereography is a sensitive gauge to monitor changes in, as well as analyze, defective posture [1].

\section{Ethics}

Written informed consent was obtained from all patients, and the study was approved by the regional ethics committee for medical research.

\section{Statistical analysis}

Data were stored and analyzed using the SPSS statistical package 19.0 (SPSS Inc. Chicago, Illinois, USA). Descriptive statistics were computed for continuous and categorical variables. Statistics included mean and standard deviations of continuous variables, frequencies, and relative frequencies of categorical factors. Testing for differences of continuous variables between the study groups was achieved by the two-sample $t$ test for independent samples or the Mann-Whitney $U$ test, as appropriate. Tests were selected by evaluating the variables for normal distribution using the Kolmogorov-Smirnov test. Comparisons between the study groups for categorical variables were done using the chi-square test or Fisher's exact test.

Comparisons within the groups between the time points of evaluation were performed with regard to percentage changes versus baseline by one-sample $t$ test against 0 , and for percentage changes between the time points named "follow-up" and "after training" by a paired $t$ test.

Alpha levels were adjusted using the Bonferroni correction, i.e., the level of significance was lowered to $0.05 / 3=0.017$.

All $p$ values resulted from two-sided statistical tests. A $p$ value $\leq 0.05$ was considered significant when no Bonferroni correction was required.

\section{Results}

Patients

Fifty patients with osteoporosis were initially recruited for the study. Of these, 25 were assigned to the PT group (conventional physiotherapy) and 25 to the ST group (sling exercises). Forty-four patients ( $88 \%$ ) aged 62 to 84 years (mean age, 70.4 years) were followed up from the start to the end of the study. Four patients in the PT group and two in the ST group terminated their participation prematurely. The reasons were illness or pain in the musculoskeletal system during the exercise sessions. The flow diagram in Fig. 3 provides an overview of the inclusion/exclusion procedure. It was designed on the basis of the statement of the Consolidated Standards of Reporting Trials and utilized common standards of randomized and controlled studies [15]. The groups did not vary significantly in respect of age (PT group 69.7 \pm 3.7 , ST group 71.0 $\pm 6.1, p=0.409$ ), fracture rates (PT group 47.6 \%, ST group $65.2 \%$ ), or gender distribution. Results for the individual domains are given below. Table 1 shows baseline characteristics of all 44 patients.

\section{Baseline characteristics}

After 3 months of exercise, significant differences were registered between the PT and the ST groups. Significant differences were also registered on pre-post comparison in the sling training group and were interpreted as individual responses to the intervention.

\section{Pain and discomfort}

Before the start of the exercise program, pain levels at rest were nearly identical in the PT and the ST exercise groups $(p>0.05)$. After 3 months of trunk stabilization training, a significant difference in pain at rest was reported by the two groups (3.1 \pm 1.7 in the PT group, $1.9 \pm 1.4$ in the ST group; $p=0.011$ ) (Table 2). The deviation from baseline levels was highly significant in the ST group $(-56.0 \pm 27.6 \%$; $p<$ $0.001)$ and not significant in the PT group $(-21.3 \pm 37.1 \%$; $p=0.019$ ) (Table 3). Comparing initial data for back pain at rest to those reported at follow-up without specific 


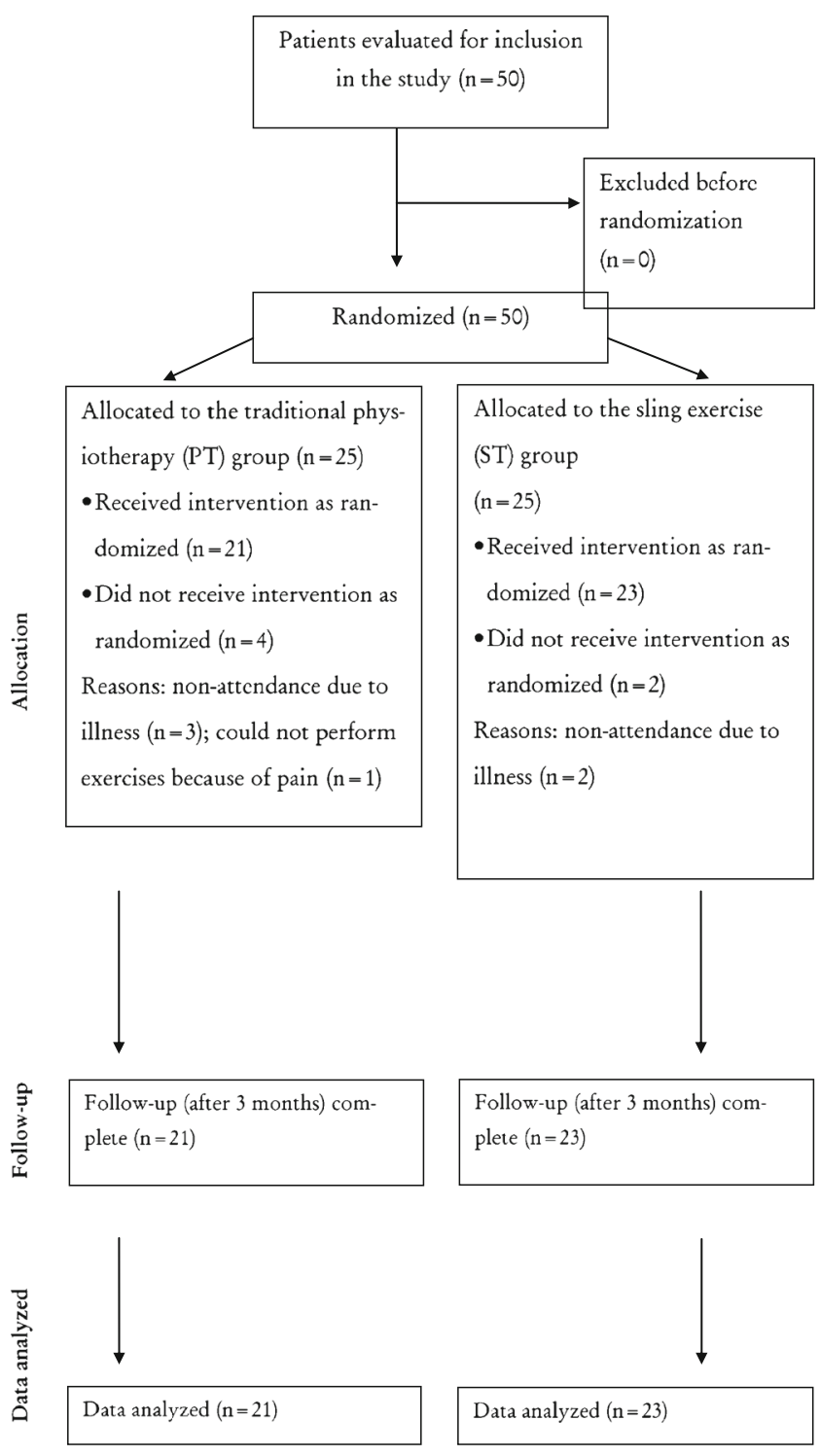

Fig. 3 Flow diagram of the inclusion/exclusion of patients during the randomized clinical study (eligibility, allocation, follow-up, and data analysis) as mentioned in the consort statement [15]

Table 1 Patient characteristics: gender: male (m)/female (f), age in years, body mass index in kilogram per square meter; bone mineral density in T-score; vertebral body fractures in numbers $(n)$; physiotherapy (PT); and sling exercise therapy (ST)

\begin{tabular}{llll}
\hline & PT $(n=21)$ & ST $(n=23)$ & $p$ value \\
\hline Gender m/f & $2 / 19$ & $2 / 21$ & $1.000^{\mathrm{a}}$ \\
Age & $69.7 \pm 3.7$ & $71.0 \pm 6.1$ & $0.409^{\mathrm{b}}$ \\
Body mass index & $23.9 \pm 2.9$ & $25.6 \pm 3.5$ & $0.084^{\mathrm{b}}$ \\
Bone mineral density & $-2.8 \pm 0.83$ & $-2.8 \pm 0.77$ & $0.809^{\mathrm{b}}$ \\
Vertebral body fractures & 10 & 15 & $0.361^{\mathrm{a}}$ \\
\hline
\end{tabular}

Data are expressed as means $\pm \mathrm{SD}$

${ }^{\text {a }}$ Fisher's exact test

${ }^{\mathrm{b}} t$ test for independent samples between the groups stabilization or strengthening exercises showed that the effect was sustained for at least 12 weeks. The improvement in the ST group was statistically very significant $(-54.9 \pm$ $48.7 \% ; p<0.001)$, while that in the PT group was not significant $(-24.2 \pm 61.4 \% ; p=0.094)$. As regards back pain during movement, no difference was registered between the groups (Table 2). Patients in both groups experienced moderate pain $(4.3 \pm 2.2$ in the PT group, $4.1 \pm 2.3$ in the ST group, $p=0.820$ ). Pain levels were reduced after the intervention, and this was confirmed on the follow-up in the sling exercise group (Table 3). The improvement in the sling exercise group was highly significant (after training vs. baseline: $-40.6 \pm 30.5 \%$; $p<0.001)$ and was even more apparent during follow-up (follow-up vs. baseline $-44.0 \pm 39.3 \% ; p<0.001$ ). Obvious but nonsignificant (after Bonferroni correction) differences were observed when initial data were compared with follow-up data in the PT group $(p=0.266)$. The difference immediately after training was highly significant (after training vs. baseline: $-22.7 \pm 22.7 \% ; p<0.001$ ).

\section{Torso strength}

On the CR test, no significant difference was registered between the two groups before the intervention was started $(p>0.05)$. A notable trend in favor of the sling exercise group was observed after the treatment program (PT 10.8 \pm 4.5 as against ST $9.0 \pm 1.8 ; p=0.096$ ). Within the groups, only the ST group showed a significant improvement at the end of the active training phase (after training vs. baseline $-25.1 \pm 16.5 \% ; p<0.001$ ). The PT group demonstrated nearly the same data as those registered at the outset (after training vs. baseline $-0.5 \pm 29.9 \% ; p=0.943$ ) (Table 3). During follow-up, the training effect in the ST group remained stable over 12 weeks (follow-up vs. baseline $-24.8 \pm 21.1 \% ; p<0.001)$. Comparison of pre-training data and those registered at follow-up in the PT group revealed no significant differences (follow-up vs. baseline $-4.6 \pm$ $25.6 \%$; $p=0.447$ ) (Table 3).

\section{Mobility}

Neither group reported major difficulties on the timed upand-go test before the start of the program $(8.3 \pm 1.7$ in the PT group, $9.0 \pm 1.9$ in the ST group; $p=0.214$ ). After the intervention, a significant difference was noted between the groups $(8.2 \pm 1.9$ in the PT group, $6.7 \pm 1.4$ in the ST group; $p=0.005$ ) (Table 2). Within the groups, only ST patients demonstrated a highly significant improvement at the end of the active training phase (after training vs. baseline $-24.5 \pm$ $13.7 \% ; p<0.001)$. Comparing data before training to those registered at follow-up in the sling exercise group revealed highly significant differences (follow-up vs. baseline $-16.3 \pm$ 
Table 2 Test results: pain at rest/during motion (numeric rating scale $0-10$ ), torso strength (chair-rising test (in seconds)), mobility (timed up-and-go test (in seconds)), kyphosis angle (in degrees), lordosis angle (in degrees), and torso lean (in degrees)

\begin{tabular}{llccc}
\hline & & PT $(n=21)$ & ST $(n=23)$ & $p$ value $^{-}$ \\
\hline Pain at rest & Baseline & $4.1 \pm 1.8$ & $4.4 \pm 1.8$ & $0.474^{\mathrm{a}}$ \\
& After training $^{\mathrm{b}}$ & $3.1 \pm 1.7$ & $1.9 \pm 1.4$ & $0.011^{\mathrm{a}}$ \\
& Follow-up $^{\mathrm{c}}$ & $3.0 \pm 2.5$ & $1.9 \pm 2.0$ & $0.112^{\mathrm{a}}$ \\
Pain during motion & Baseline & $4.3 \pm 2.2$ & $4.1 \pm 2.3$ & $0.820^{\mathrm{a}}$ \\
& After training & $3.3 \pm 1.9$ & $2.6 \pm 1.8$ & $0.174^{\mathrm{a}}$ \\
Chair-rising test & Follow-up & $3.5 \pm 2.1$ & $2.6 \pm 1.8$ & $0.147^{\mathrm{a}}$ \\
& Baseline & $11.0 \pm 4.0$ & $12.6 \pm 3.3$ & $0.149^{\mathrm{a}}$ \\
& After training & $10.8 \pm 4.5$ & $9.0 \pm 1.8$ & $0.096^{\mathrm{a}}$ \\
Timed up-and-go test & Follow-up & $10.2 \pm 3.7$ & $9.1 \pm 2.7$ & $0.254^{\mathrm{a}}$ \\
& Baseline & $8.3 \pm 1.7$ & $9.0 \pm 1.9$ & $0.214^{\mathrm{a}}$ \\
& After training & $8.2 \pm 1.9$ & $6.7 \pm 1.4$ & $0.005^{\mathrm{a}}$ \\
Kyphosis angle & Follow-up & $8.3 \pm 2.1$ & $7.4 \pm 1.9$ & $0.191^{\mathrm{a}}$ \\
& Baseline & $53.6 \pm 8.8$ & $59.2 \pm 8.7$ & $0.042^{\mathrm{a}}$ \\
& After training & $51.9 \pm 9.6$ & $57.3 \pm 8.7$ & $0.054^{\mathrm{a}}$ \\
& Follow-up & $52.6 \pm 9.0$ & $56.1 \pm 9.3$ & $0.222^{\mathrm{a}}$ \\
Lordosis angle & Baseline & $41.2 \pm 11.9$ & $45.3 \pm 8.6$ & $0.192^{\mathrm{a}}$ \\
& After training & $41.1 \pm 10.4$ & $43.9 \pm 8.0$ & $0.331^{\mathrm{a}}$ \\
& Follow-up & $40.7 \pm 11.7$ & $46.2 \pm 11.2$ & $0.128^{\mathrm{a}}$ \\
& Baseline & $4.8 \pm 2.4$ & $5.4 \pm 4.1$ & $0.595^{\mathrm{a}}$ \\
& After training & $4.9 \pm 2.2$ & $5.1 \pm 3.2$ & $0.884^{\mathrm{a}}$ \\
& Follow-up & $4.7 \pm 2.5$ & $5.3 \pm 3.4$ & $0.536^{\mathrm{a}}$ \\
\hline
\end{tabular}

Data are expressed as means \pm

$\mathrm{SD}$

${ }^{\mathrm{a}} t$ test for independent samples between the groups

${ }^{\mathrm{b}}$ Three months

${ }^{\mathrm{c}} \mathrm{Six}$ months

$p=0.652$ ). Similar data were observed at the follow-up investigation (follow-up vs. baseline $-0.9 \pm 15.2 \% ; p=0.791$ ).

$16.9 \% ; p<0.001)$ (Table 3). A marginal change was observed

Table 3 Test results of percentage changes: pain at rest/with movement (numeric rating scale $0-10$ ), torso strength (chair-rising test (in seconds)), mobility (timed up-and-go test (in seconds)), kyphosis angle (in degrees), lordosis angle (in degrees), and torso lean (in degrees)

Data are expressed as means \pm SD

${ }^{\mathrm{a}}$ Comparison in after training vs. baseline (one-sample $t$ test against 0 )

${ }^{\mathrm{b}}$ Comparison in follow-up vs. baseline (one-sample

$t$ test against 0 )

${ }^{\mathrm{c}}$ Comparison in follow-up vs. after training (paired $t$ test)

\begin{tabular}{|c|c|c|c|c|c|}
\hline & After training vs. baseline & Follow-up vs. baseline & $p$ value $^{\mathrm{a}}$ & $p$ value $^{\mathrm{b}}$ & $p$ value $\mathrm{c}^{\mathrm{c}}$ \\
\hline \multicolumn{6}{|l|}{ Pain at rest } \\
\hline $\mathrm{PT}(n=21)$ & $-21.3 \pm 37.1$ & $-24.2 \pm 61.4$ & 0.019 & 0.094 & 0.729 \\
\hline $\mathrm{ST}(n=23)$ & $-56.0 \pm 27.6$ & $-54.9 \pm 48.7$ & $<0.001$ & $<0.001$ & 0.923 \\
\hline \multicolumn{6}{|c|}{ Pain during motion } \\
\hline $\mathrm{PT}(n=21)$ & $-22.7 \pm 22.7$ & $-13.5 \pm 51.6$ & $<0.001$ & 0.266 & 0.624 \\
\hline $\mathrm{ST}(n=23)$ & $-40.6 \pm 30.5$ & $-44.0 \pm 39.3$ & $<0.001$ & $<0.001$ & 0.883 \\
\hline \multicolumn{6}{|c|}{ Chair-rising test } \\
\hline $\mathrm{PT}(n=21)$ & $-0.5 \pm 29.9$ & $-4.6 \pm 25.6$ & 0.943 & 0.447 & 0.272 \\
\hline $\mathrm{ST}(n=23)$ & $-25.1 \pm 16.5$ & $-24.8 \pm 21.1$ & $<0.001$ & $<0.001$ & 0.939 \\
\hline \multicolumn{6}{|c|}{ Timed up-and-go test } \\
\hline $\mathrm{PT}(n=21)$ & $-1.5 \pm 14.8$ & $-0.9 \pm 15.2$ & 0.652 & 0.791 & 0.832 \\
\hline $\mathrm{ST}(n=23)$ & $-24.5 \pm 13.7$ & $-16.3 \pm 16.9$ & $<0.001$ & $<0.001$ & 0.004 \\
\hline \multicolumn{6}{|c|}{ Kyphosis angle } \\
\hline $\mathrm{PT}(n=21)$ & $-3.4 \pm 6.8$ & $-1.7 \pm 7.9$ & 0.034 & 0.339 & 0.510 \\
\hline $\mathrm{ST}(n=23)$ & $-4.5 \pm 8.0$ & $-4.8 \pm 8.5$ & 0.013 & 0.014 & 0.008 \\
\hline \multicolumn{6}{|c|}{ Lordosis angle } \\
\hline $\mathrm{PT}(n=21)$ & $1.1 \pm 8.0$ & $0.8 \pm 20.9$ & 0.551 & 0.858 & 0.772 \\
\hline $\mathrm{ST}(n=23)$ & $-2.9 \pm 6.9$ & $1.1 \pm 11.7$ & 0.056 & 0.676 & 0.126 \\
\hline \multicolumn{6}{|l|}{ Torso lean } \\
\hline $\mathrm{PT}(n=21)$ & $-3.4 \pm 6.7$ & $4.6 \pm 54.7$ & 0.266 & 0.703 & 0.386 \\
\hline $\mathrm{ST}(n=23)$ & $-4.1 \pm 56.7$ & $-1.0 \pm 79.6$ & 0.733 & 0.955 & 0.437 \\
\hline
\end{tabular}




\section{Posture}

Raster stereography was performed to obtain additional data about the shape of the spine. The technique was developed for optical measurement of the shape of the spine and biomechanical analysis of spinal geometry [8]. Owing to the very nature of osteoporosis, a specific standard cannot be postulated for posture parameters. We are aware of no comparative studies in which VRS has been used to document posture in osteoporosis patients.

At the start of the exercise series, a significant difference in the kyphosis angle was noted between the PT group and the ST group (53.6 \pm 8.8 vs. $59.2 \pm 8.7 ; p=0.042)$. After the intervention, the difference was no longer significant $(51.9 \pm$ 9.6 vs. $57.3 \pm 8.7 ; p>0.05)$. Follow-up investigations revealed no significant differences between the intervention groups $(p>0.05)$. Within the groups, only ST patients demonstrated a significant improvement at the end of the active training phase (after training vs. baseline $-4.5 \pm 8.0 \%$; $p=$ 0.013). A significant difference was found between the data registered before training and those registered at follow-up in the sling exercise group (follow-up vs. baseline $-4.8 \pm$ $8.5 \% ; p=0.014$ ) (Table 3 ). Comparison of follow-up vs. post-training revealed a significant difference in the sling exercise group $(p=0.008)$. The lordosis angle did not differ significantly either between or within the groups (Tables 2 and 3).

Torso lean (in degrees) refers to the difference in height between VP and DM on the sagittal section. No significant difference was noted between the PT and ST exercise groups before the start of the study (PT $4.8 \pm 2.4$ vs. ST $5.4 \pm 4.1$, $p>0.05)$. Likewise, no significant difference within both groups was registered in respect of this parameter either post-intervention or on follow-up $(p>0.05)$.

\section{Discussion}

Osteoporosis and alterations of the spine resulting from it lead to back pain. The causes of pain are many-faceted and not immediately related to vertebral deformation. Muscle loss and muscular imbalance may be one reason. The results of the present study show that a sling exercise program leads to upright posture and reduces the kyphosis angle. Markedly improved strength in the trunk (chair-rising test) and better mobility (timed up-and-go test) are responsible for significant pain relief during motion and at rest. To our knowledge, the data registered after sling therapy in patients with osteoporosis have not been previously reported.

The recent published literature contains reports on various types of training programs. In an investigation of 100 postmenopausal women with osteoporosis, aged between 55 and 75 years, Teixeira et al. [29] concluded that progressive muscle training of the quadriceps muscle and proprioception leads to muscular and coordinative adjustments; this exerts a positive effect on the risk of falls and quality of life in patients with osteoporosis. The authors did not register the patients' intake of painkillers.

Iwamoto et al. [11] conducted a 5-month training program in 68 patients aged 76.4 years on average. After completion of the training program, marked improvements were registered in respect of muscle strength and walking ability, while the frequency of falls was significantly reduced.

In 69 postmenopausal women with osteoporosis, aged between 50 and 70 years, Siegrist et al. [26] found that strength training performed twice a week has effects on muscle strength, dynamic performance capacity, and wellbeing. No patient had been taking painkillers on a regular or permanent basis.

Franck et al. [10] report that a mere 4 weeks of exercise is sufficient to enhance functional abilities in patients with osteoporosis as well as reduce their physical symptoms (back pain, heavy legs).

The concept of sling exercise therapy has the same purpose, but the use of a sensomotor approach to treat pain in osteoporosis is new. The neuromuscular system is subjected to numerous stimuli because of the variability of the slings. Patients must concentrate and react very rapidly to regulate and control their movements with a small supporting surface. The purpose is to activate the deep and joint-supporting muscles of the spine (the multifidus and transversus abdominis muscles, the pelvic floor, and the diaphragm), which are very important for stabilization of the lumbar spine and alleviation of pain in this region [9, 14, 16, 17, 24].

Instability is a result as well as cause of degenerative disorders. Degeneration of intervertebral disks leads to instability, although it may not necessarily be accompanied by pain. Instability of the spine is associated with a high risk of injury due to external factors, such as lifting heavy weights $[13,14,18]$.

All of the abovementioned training programs and exercises improved muscle strength and reduced pain. However, these studies contain no information about the kyphosis angle. Based on experimental data reported by BoeckhBehrens and Buskies [5], who sought to optimize exercise programs on the basis of electromyographic recordings, it may be concluded that the exercises performed in the present study were effective.

We used the method of video raster stereography, which registers posture parameters such as the kyphosis or lordosis angle without the use of radiation. An interesting finding in the present study was the reduction of the kyphosis angle. This appears to have been due to the dorsal muscles of the musculus erector spinae. Especially the lateral muscles (musculus longissimus, musculus iliocostalis) have long muscle bundles that insert at every bone segment (rib or 
transverse process) and also form new origins. Extending from the sacral bone (os sacrum) to the occiput, the muscle's fixation in the pelvis is responsible for its strong lifting arms. These are important for an erect trunk, its lateral inclination, and rotation [21]. Besides, we presume that the medial muscles (musculus multifidus, musculus spinales) were subjected to loads because of the intervention.

In a cross-section study, Sinaki et al. [28] proved that muscle strength in the extensors of the spine, the kyphosis angle, and vertebral fractures are closely interrelated. The authors conclude that stronger back muscles counteract advancing kyphosis of the chest and reduce the risk of vertebral fractures. Recent studies corroborate these concepts $[6,27]$.

However, the significant difference in the kyphosis angle between our groups at baseline is difficult to explain. We presume that this resulted from the size of the random sample on the one hand and the larger number of vertebral body fractures in the sling exercise group on the other.

\section{Conclusions}

- Sling exercise therapy has a positive effect on torso stability and posture in osteoporosis patients with chronic back pain.

- Sling exercise therapy alleviates pain and improves function in osteoporosis patients.

- This type of intervention is a helpful preventive measure because it influences the daily life of osteoporosis patients by reducing the risk of falls.

- Sling exercise therapy is a useful supplement to existing treatments for osteoporosis.

Conflict of interest The authors have no conflict of interest to declare.

Informed consent For studies with human subjects: All procedures followed were in accordance with the ethical standards of the responsible committee on human experimentation (institutional and national) and with the Helsinki Declaration of 1975, as revised in 2000. Informed consent was obtained from all patients for being included in the study.

\section{References}

1. Asamoah V, Mellerowicz H, Venus J, Klöckner C (2000) Oberflächenvermessung des Rückens. Wertigkeit in der Diagnostik der Wirbelsäulenerkrankungen. Der Orthopäde 29(6):480-9

2. Basler HD (2011) Akutschmerztherapie in Pädiatrie und Geriatrie Schmerzmessung: Welche Schmerzskala bei welchen Patienten? Anästhesiol Intensivmed Notfallmed Schmerzther 46(5):33442

3. Baum E, Peters KM (2008) Primäre Osteoporose - leitliniengerechte Diagnostik und Therapie. Deutsches Ärzteblatt 105(33):573-82
4. Bergland A, Thorsen H, Kåresen R (2010) Effect of exercise on mobility, balance, and health-related quality of life in osteoporotic women with a history of vertebral fracture: a randomized, controlled trial. Osteoporos Int 22(6):1863-71

5. Boeckh-Behrens W, Buskies W (2010) Fitness-Kraftraining. Die besten Übungen und Methoden für Sport und Gesundheit. 14. Aufl., Orig.-Ausg. Reinbek bei Hamburg: Rowohlt-Taschenbuch-Verl

6. Borgo MJ, Sinaki M (2010) Back progressive resistive exercise program to reduce risk of vertebral fractures. Journal für Mineralstoffwechsel 17(2):66-71

7. de Kam D, Smulders E, Weerdesteyn V, Smits-Engelsman BC (2009) Exercise interventions to reduce fall-related fractures and their risk factors in individuals with low bone density: a systematic review of randomized controlled trials. Osteoporos Int 20(12):2111-25

8. Drerup B, Ellger B, zu Meyer Bentrup F, Hierholzer E (2001) Rasterstereografische Funktionsaufnahmen. Eine neue Methode der biomechanischen Analyse der Skelettgeometrie. Der Orthopäde 30(4):242-50

9. Ershad N, Kahrizi S, Abadi MF, Zadeh SF (2009) Evaluation of trunk muscle activity in chronic low back pain patients and healthy individuals during holding loads. Journal of Back and Musculoskeletal Rehabilitation 22(3):165-72

10. Franck H, Hohmann W (2001) Verbesserung der Funktionskapazität, der Schmerzhaftigkeit und der Leistungsfähigkeit bei Patienten mit Osteoporose durch ein spezielles Sportrehabilitationstraining. Deutsche Zeitschrift für Sportmedizin 52(2):63-7

11. Iwamoto J, Suzuki H, Tanaka K et al (2009) Preventative effect of exercise against falls in the elderly: a randomized controlled trial. Osteoporos Int 20(7):1233-40

12. Kirkesola G (2001) Sling Exercise Therapy - ein Konzept zur Behandlung von Beschwerden am Bewegungssystem. Zeitschrift für Physiotherapeuten 53(3):428-38

13. McGill SM (1998) Low back exercises. Evidence for improving exercise regimens. Phys Ther 78(7):754-65

14. Meier H (2006) Neue Aspekte der Gelenkstabilisation - das SlingTraining. Leistungssport 2:19-23

15. Moher D, Schulz KF, Altman DG (2005) Das CONSORT Statement. Überarbeitete Empfehlungen zur Qualitätsverbesserung von Reports randomisierter Studien im Parallel-Design. Der Schmerz 19(2):156-62

16. O'Sullivan PB, Twomey LT, Allison GT (1997) Evaluation of specific stabilizing exercise in the treatment of chronic low back pain with radiologic diagnosis of spondylolysis or spondylolisthesis. Spine 22(24):2959-67

17. O'Sullivan PB, Twomey LT, Allison GT, Sinclair J, Miller K, Knox J (1997) Altered patterns of abdominal muscle activation in patients with chronic low back pain. Australian Journal of Physiotherapy 43(2):91-8

18. Panjabi M (1992A) The stabilising system of the spine. Part I. Function, dysfunction, adaption and enhancement. Journal of Spinal Disorders 5(4):383-9

19. Podsiadlo D, Richardson S (1991) The timed "up and go": a test of basic functional mobility for frail in elderly persons. J Am Geriatr Soc 39(2):142-8

20. Preisinger E (2009) Physiotherapie und Bewegung bei Osteoporose und Folgeerkrankungen. Z Rheumatol 68(7):534-8

21. Rohen JW, Lütjen-Drecoll E (2006) Rohen-Lütjen-Drecoll. Funktionelle Anatomie des Menschen. Lehrbuch der makroskopischen Anatomie nach funktionellen Gesichtspunkten; mit 44 Tabellen. 11, überarb. und erw. Aufl. Schattauer, Stuttgart

22. Rosenberger WF, Lachin JM (2002) Randomization in clinical trials. Theory and practice [monograph on the Internet]. New York: Wiley. Internet: http://site.ebrary.com/lib/alltitles/ docDetail.action?docID=10275034.

23. Salkeld G, Cameron ID, Cumming RG et al (2000) Quality of life related to fear of falling and hip fracture in older women: a time trade off study. British Medical Journal 320(7231):341-6 
24. Schmoll S, Hahn D, Schwirtz A (2008) Die Behandlung von chronischem LWS-Schmerz mithilfe des S-E-T - Konzeptes (SlingExercise-Therapy). Bewegungstherapie und Gesundheitssport 24(2):52-9

25. Schwesig R, Müller K, Hottenrott K et al (2006) Sensomotorisches Training im Alter und bei Osteoporose. Bewegungstherapie und Gesundheitssport 22(2):62-8

26. Siegrist M, Lammel C, Jeschke D (2006) Krafttraining an konventionellen bzw. oszillierenden Geräten und Wirbelsäulengymnastik in der Prävention der Osteoporose bei postmenopausalen Frauen. Deutsche Zeitschrift für Sportmedizin 57(7/8):182-8

27. Sinaki M (2010) Musculoskeletal rehabilitation in patients with osteoporosis-rehabilitation of osteoporosis program-exercise (ROPE). Journal für Mineralstoffwechsel 17(2):60-5

28. Sinaki M, Wollan PC, Scott RW et al (1996) Can strong back extensors prevent vertebral fractures in women with osteoporosis? Mayo Clin Proc 71(10):951-6
29. Teixeira LEPP, Silva KNG, Imoto AM et al (2010) Progressive load training for the quadriceps muscle associated with proprioception exercises for the prevention of falls in postmenopausal women with osteoporosis: a randomized controlled trial. Osteoporos Int 21(4):589-96

30. Uhlemann C, Lange U (2006) Differenzialindikative physikalische Therapiestrategien der Osteoporose. Empfehlungen für den Praxisalltag. Z Rheumatol 65(5):407-16

31. von Stengel S, Kemmler W, Engelke K et al (2011) Effects of whole body vibration one bone mineral density and falls: results of the randomized controlled ELVIS study with postmenopausal women. Osteoporos Int 22(1):317-25

The author concerned would like to point out the following: A Formetric III 4D instrument produced by Diers International and made available for the period of investigation was used for the rasterstereographic photographs. 